RESEARCH

Turkish Journal of Geriatrics

DOI: $10.31086 /$ tjgeri.2021.233

2021; 24(3): 359-369

- Gözde EROL ${ }^{1}$

- İsmail AYTAÇ ${ }^{1}$

- Betül GÜVEN AYTAÇ ${ }^{1}$

CORRESPONDANCE

${ }^{1}$ Issmail AYTAÇ

Ankara City Hospital, Department of

Anesthesiology and Reanimation, ANKARA, Turkey

Phone: +905056340369

e-mail: aytacismail1972@gmail.com

Received: Apr 05, 2021

Accepted: Aug 29, 2021

${ }^{1}$ Ankara City Hospital, Department of Anesthesiology and Reanimation, ANKARA, Turkey

\section{DO SHOCK INDEX, MODIFIED SHOCK INDEX, AND SHOCK INDEX BY AGE HAVE A PREDICTIVE VALUE IN DETERMINING THE RISK OF POST-SPINAL HYPOTENSION IN ELDERLY PATIENTS?}

\section{Abstract}

Introduction: Intraoperative hypotension in the elderly, is associated with an increased risk of complications. Predicting intraoperative hypotension will help patients have better outcomes by providing early prevention and intervention. We investigated the predictive value of the shock index, modified shock index, and shock index by age to determine the risk of hypotension in elderly patients undergoing spinal anesthesia in minor elective surgeries.

Materials and Methods: Our prospective observational study included 128 patients aged $\geq 65$ with ASA classifications of I-III undergoing minor elective surgeries under spinal anesthesia lasting $<120$ minutes. The patients' preoperative shock index, modified shock index, and shock index by age values were calculated and recorded. Hypotension was defined as mean arterial pressure $\leq 65 \mathrm{mmHg}$ on two consecutive measurements or $<25 \%$ of the baseline value. Hypotensive and normotensive patients' preoperative shock index, modified shock index, and shock index by age values, as well as whether they were admitted to the post-anesthesia care unit, discharge time, and complication rates, were all compared.

Results: The incidence of intraoperative hypotension was $50 \%(n=64)$. The modified shock index has predictive value for predicting hypotension (cut-off point of <0.73). Being female increased the risk of hypotension by 20.047 fold, and a 1-point increase in Charlson Comorbidity Index scores increased the risk of hypotension by 2.058 fold.

Conclusion: The modified shock index arrived at by dividing heart rate by mean arterial pressure, can be used to predict hypotension due to spinal anesthesia in elderly patients.

Keywords: Anesthesia, Spinal; Geriatrics; Hypotension. 


\section{INTRODUCTION}

The vascular stiffening observed in the cardiac physiology, autonomic changes, and an increase in the incidence of systolic and diastolic dysfunction make the elderly susceptible to hypotension after anesthesia (1-3). Therefore, the most common intraoperative complication in the elderly is hypotension (4).

It has been shown that an intraoperative decrease of mean arterial pressure (MAP) to $<80 \mathrm{mmHg}$ for $>10$ minutes can disrupt tissue perfusion and cause organ damage (3). Even short-term systolic or MAP drops during noncardiac surgery may result in major cardiac and renal complications $(5,6)$. The use of preoperative fluid boluses (preloading) in minor surgeries has been shown to improve hemodynamic stability (7). While preoperative dehydration is a preventable factor, preloading therapy is risky and not recommended in elderly patients, due to the high prevalence of cardiac, respiratory, and renal comorbidities (8).

The shock index (SI) is a straightforward equation obtained by dividing the heart rate (HR) by systolic blood pressure. The shock index has a standard range from 0.5 to 0.7 . It increases in cases of acute hypovolemia and left ventricular dysfunction, and it aids in the early diagnosis of shock (9). The modified shock index (MSI) is a value arrived at by dividing HR by MAP. It indicates organ perfusion status better than systolic blood pressure (SBP) because it includes the diastolic blood pressure parameter when calculating MAP. The normal value of MSI is between 0.7 and $1.3(10,11)$. Because age has a negative impact on physiological reserve, a shock index by age (SIA) has been created for the elderly, and it is found by multiplying age and SI. If the SIA value is greater than 50, particularly in patients over 55, life-threatening shock may be observed. Additionally, SI, MSI, and SIA are parameters that can be easily measured without the use of any special equipment in the estimation of mortality and morbidity (12-15). Pre-intubation SI, MSI, and SIA values have been shown to be independent predictors of post-intubation hypotension in studies evaluating $\mathrm{SI}, \mathrm{MSI}$, and SIA to predict post-intubation hypotension $(15,16)$.

Hypovolemia and hypovolemic shock cannot be diagnosed solely based on heart rate or blood pressure parameters. Thus, the shock index should be investigated to determine whether it can be used as a clinical indicator of mortality $(14,17,18)$.

Predicting intraoperative hypotension, taking early precautions, and intervening can also be beneficial in the elderly population. Our primary goal in this study is to determine whether $\mathrm{SI}, \mathrm{MSI}$, and SIA, as non-invasive parameters that can be measured using only heart rate and blood pressure parameters at the bedside, can predict post-spinal hypotension in patients over 65 years old undergoing elective transurethral interventions.

Our secondary goal is to investigate whether intraoperative hypotension has any adverse effects by comparing pre-operative and post-operative blood tests, as well as whether the post-anesthesia care unit (PACU) was visited, the duration of hospital stay, and postoperative complications.

\section{MATERIALS AND METHODS}

This study began after the approval of the Turkish Ministry of Health, Ankara City Hospital, No. 1 Clinical Research Ethics Committee Presidency (approval number E1-20-787 dated 25/06/20). Clinical trial number (NCT04483765) was obtained. Our study is a prospective, observational study and was conducted in Ankara City Hospital between 01/07/2020 and 01/11/2020. Informed consent was obtained from all patients.

The study involved 128 patients $\geq 65$ years old who had American Society of Anesthesiologists (ASA) risk scores of I-III, undergone elective transurethral bladder (TUR-B) and prostate resections (TUR-P) under spinal anaesthesia, and surgery times $\leq 120$ minutes. The existence of valvular disease and 
arrhythmia that impaired hemodynamics (for example, high ventricular fast atrial fibrillation), severe heart failure, mental/motor problems that made communicating difficult, neuropsychiatric disease in the patient, and the patient's refusal to participate in the study were accepted as exclusion criteria.

Patients' ages, heights, body weights, body mass indices (BMls), genders, Charlson Comorbidity Index $(\mathrm{CCl})$ values according to their systemic diseases, pre-operative fasting times, pre-operative HRs, non-invasive SBPs, diastolic blood pressures (DBPs), MAP values, and peripheral oxygen saturation $\left(\mathrm{SpO}_{2} \mathrm{~s}\right)$ values were recorded. The patients' preoperative $\mathrm{SI}, \mathrm{MSI}$, and SIA values were calculated and recorded.

Blood urea nitrogen (BUN), creatine, glomerular filtration rate (GFR), aspartate aminotransferase (AST), alanine aminotransferase (ALT), hemoglobin $(\mathrm{Hgb})$, hematocrit $(\mathrm{Htc})$, and white blood cell count (WBC) values were recorded from the blood tests performed during the pre-operative and post-operative periods. The type of operation that patients were to undergo, operation time, and HR, SBP, DBP, $\mathrm{MAP}$, and $\mathrm{SpO}_{2}$ values were recorded every $5 \mathrm{~min}$ utes in the first 30 minutes of the operation, every 10 minutes after the operation, and every 15 minutes after the 60th post-operative minute. Furthermore, the needle thickness used in spinal anesthesia, the amount of dermatome used for spinal anesthesia, the local anesthetics and doses used for spinal anesthesia, and the sedative drugs applied to the patient and their doses were all recorded.

The amount of total crystalloid/colloid fluid applied intravenously (i.v.) during the intraoperative period and the amount $(\mathrm{L})$ and type of irrigation fluid used during the TUR operation were recorded.

For the first 15 minutes after spinal anesthesia, the sensory block level was determined by applying cold to the patient's skin with an ice tray once per minute. By comparing the patient's shoulder to the dermatome areas of the abdominal skin, where the block was tested, the block level was evaluated based on the patient's verbal responses. The time elapsed from the moment of spinal anesthesia to the detection of the sensory block was recorded as the onset of sensory block. The patient's sensory block level was recorded as the level of the sensory block that remained constant over three measurements.

Motor block was assessed using the Bromage Scale every 5 minutes. The time elapsed from the moment of spinal anesthesia to the detection of motor block was recorded as the onset of motor block. The evaluation that remained constant three times in a row was recorded as the degree of motor block.

The patient's admissions to the service or PACU, hospitalization times (discharge time), and whether or not there were any postoperative complications were all reported during the postoperative period.

Patients were accepted as hypotensive when two consecutive MAP measurements were $\leq 65$ $\mathrm{mmHg}$ or when MAP was $<25 \%$ (improved or not improved with intervention) of the baseline value. Normotensive patients were labeled as Group $\mathrm{N}$, whereas hypotensive patients were labeled as Group H. Demographic characteristics (age, gender, and comorbidities) were also compared between these groups.

\section{Statistical Analysis}

The descriptive statistics for the continuous data have been presented as mean, standard deviation, median, minimum, and maximum values, whereas the discrete data have been presented in percentages. The Kolmogorov-Smirnov test was used to assess the data's conformity to a normal distribution. The t-test was used to compare continuous data with a normal distribution in hypotensive and non-hypotensive patients, and the Mann-Whitney $U$ test was used to compare non-normally distributed data. In group comparisons of nominal variables (cross tables), the Chi-Square and Fisher's Exact tests were used. The risk factors affecting the 
development of hypotension were investigated using multivariate logistic regression analysis. For the evaluations, the IBM SPSS Statistics 20 program was used, and the statistical significance limit was accepted at $p<0.05$.

\section{Sample Size}

Lee et al. found that the rate of hypotension after intubation was $29 \%$ in a study that evaluated the use of SI, MSI, and SIA in hypotension prediction after intubation (15). At a $d=0.12$ effect size, $80 \%$ power, and $\mathbf{a}=0.05$ error level, 127 patients should be recruited into our analysis, assuming that the rate of hypotension in patients may be 10 percentage different. The calculation was performed using the G*Power 3.1.9.4 statistical package program.

\section{RESULTS}

When patients were accepted as hypotensive when two consecutive MAP measurements made at any time from spinal anesthesia until the end of surgery with $\leq 65 \mathrm{mmHg}$ or when MAP was $<25 \%$ of the preoperative baseline value, $n=64(50 \%)$ of patients were found to have developed hypotension.
When the demographic characteristics of Group $\mathrm{H}$ and Group N were compared, it was discovered that the patients in Group $\mathrm{H}$ had a higher mean ages $(p<0.05)$, shorter average height $(p<0.01)$, higher mean $\mathrm{CCl}$ scores $(p<0.05)$, and higher ratio of ASA scores that were 3 (Table 1, $p<0.01$ ). Group H had a slightly higher female gender ratio than Group N ( $p$ $<0.01)$. Body weight, BMI values, surgery form and length, and fasting periods were identical in Group $\mathrm{H}$ and Group N ( $\mathrm{p}>0.05)$.

Group $\mathrm{H}$ and Group N had identical preoperative BUN, creatine, GFR, ALT, Hgb, Htc, WBC, and $\mathrm{SpO}_{2}$ values $(\mathrm{p}>0.05)$, while AST values were higher in Group H (Table 1, $\mathrm{p}<0.05)$.

When the applied level of intervertebral space rates of Group H and Group N were compared, Group $\mathrm{H}$ had a higher application rate at the L3-L4 level than Group N ( $n=34,53.1 \%, n=15,23.4 \%, p$ $<0.001$, respectively), and the rate at the L5-S1 level was lower in Group $\mathrm{H}(\mathrm{n}=2,3.1 \%, \mathrm{n}=22,34.4 \%$, $\mathrm{p}$ $<0.001$, respectively).

The spinal needle thickness (Gauge) used in Groups N and H was no different ( $p>0.05)$. The

Table 1. Comparison of Demographic Characteristics, Preoperative Laboratory Parameters of Normotensive Patients (Group N) and Hypotensive Patients (Group H)

\begin{tabular}{|c|c|c|c|c|}
\hline & Group N & Group H & \multirow[b]{2}{*}{ Test Statistics } & \multirow[b]{2}{*}{$p$} \\
\hline & $\begin{array}{c}\text { Mean } \pm \text { SD } \\
\text { Median (Min-Max) }\end{array}$ & $\begin{array}{c}\text { Mean } \pm \text { SD } \\
\text { Median (Min-Max) }\end{array}$ & & \\
\hline Age (years) & $\begin{array}{c}72.09 \pm 5.89 \\
70(65-88)\end{array}$ & $\begin{array}{c}75.20 \pm 6.97 \\
76(65-89)\end{array}$ & $U=1526.5$ & 0.013 \\
\hline Body Weight (kg) & $\begin{array}{c}75.61 \pm 13.99 \\
73(44-108)\end{array}$ & $\begin{array}{l}76.28 \pm 13.71 \\
75.5(50-107)\end{array}$ & $t=-0.274$ & 0.784 \\
\hline Height (cm) & $\begin{array}{c}172.06 \pm 7.70 \\
172(150-192)\end{array}$ & $\begin{array}{c}168.22 \pm 7.97 \\
169(150-182)\end{array}$ & $t=2.773$ & 0.006 \\
\hline BMI $\left(k g / m^{2}\right)$ & $\begin{array}{c}25.48 \pm 4.14 \\
24.78(15.22-40)\end{array}$ & $\begin{array}{c}26.87 \pm 3.94 \\
26.85(18.73-35.36)\end{array}$ & $t=-1.944$ & 0.054 \\
\hline Surgery time (minutes) & $\begin{array}{c}51.56 \pm 24.20 \\
50(20-120)\end{array}$ & $\begin{array}{l}45.86 \pm 19.79 \\
42.5(20-115)\end{array}$ & $U=1771.0$ & 0.184 \\
\hline
\end{tabular}




\begin{tabular}{|c|c|c|c|c|}
\hline Fasting time (hours) & $\begin{array}{l}10.81 \pm 2.06 \\
10(8-16)\end{array}$ & $\begin{array}{l}11.02 \pm 1.92 \\
10.5(8-16)\end{array}$ & $U=1929.0$ & 0.560 \\
\hline Charlson Index & $1.5(0-6)$ & $2(0-6)$ & $U=1585.5$ & 0.023 \\
\hline $\mathrm{BUN}(\mathrm{mg} / \mathrm{dL})$ & $\begin{array}{c}47.72 \pm 22.26 \\
44.5(0.40-155)\end{array}$ & $\begin{array}{l}43.98 \pm 17.19 \\
42.5(19-117)\end{array}$ & $U=1767.0$ & 0.289 \\
\hline Creatinine $(\mathrm{mg} / \mathrm{dL})$ & $\begin{array}{c}1.08 \pm 0.52 \\
0.93(0.45-3.57)\end{array}$ & $\begin{array}{c}1.06 \pm 0.33 \\
0.98(0.42-2.0)\end{array}$ & $U=1896.0$ & 0.469 \\
\hline $\mathrm{GFR}(\mathrm{ml} / \mathrm{min})$ & $\begin{array}{c}74.33 \pm 20.62 \\
80(16-113)\end{array}$ & $\begin{array}{c}69.73 \pm 21.78 \\
75(30-129)\end{array}$ & $U=1723.5$ & 0.122 \\
\hline AST (U/L) & $\begin{array}{c}19.90 \pm 12.79 \\
17(7-83)\end{array}$ & $\begin{array}{l}21.57 \pm 9.04 \\
20.5(8-58)\end{array}$ & $U=1400.5$ & 0.026 \\
\hline $\operatorname{ALT}(U / L)$ & $\begin{array}{c}20.86 \pm 12.22 \\
19(6-77)\end{array}$ & $\begin{array}{c}22.37 \pm 13.07 \\
19(5-74)\end{array}$ & $U=1591.5$ & 0.619 \\
\hline $\mathrm{Hgb}(\mathrm{g} / \mathrm{dL})$ & $\begin{array}{c}13.18 \pm 2.03 \\
13.15(8.7-18.2)\end{array}$ & $\begin{array}{c}13.00 \pm 2.16 \\
13.2(7-19.1)\end{array}$ & $t=0.497$ & 0.620 \\
\hline $\mathrm{Htc}(\%)$ & $\begin{array}{l}40.23 \pm 7.23 \\
41.1(3-56)\end{array}$ & $\begin{array}{c}40.12 \pm 6.12 \\
41.3(21.6-56.3)\end{array}$ & $U=1992.0$ & 0.790 \\
\hline WBC $(\mu \mathrm{L} / \mathrm{ml})$ & $\begin{array}{c}7.78 \pm 2.23 \\
7.32(4.51-17.31)\end{array}$ & $\begin{array}{c}7.55 \pm 2.62 \\
6.94(2.15-17.61)\end{array}$ & $U=1868.0$ & 0.391 \\
\hline \multirow[t]{2}{*}{$\mathrm{SpO}_{2}(\%)$} & $\begin{array}{l}95.17 \pm 2.05 \\
95(90-100)\end{array}$ & $\begin{array}{l}94.73 \pm 1.93 \\
95(90-98)\end{array}$ & $U=1802.5$ & 0.236 \\
\hline & $n(\%)$ & $n(\%)$ & Test Statistics & $p$ \\
\hline \multicolumn{5}{|l|}{ Gender } \\
\hline Female & $2(3.1)$ & $11(17.2)$ & \multirow{2}{*}{$x^{2}=6.935$} & \multirow{2}{*}{0.008} \\
\hline Male & $62(96.9)$ & $53(82.8)$ & & \\
\hline \multicolumn{5}{|l|}{ Type of surgery } \\
\hline TUR-P & 30 (46.9) & $22(34.4)$ & \multirow{2}{*}{$x^{2}=2.073$} & \multirow{2}{*}{0.150} \\
\hline TUR-B & $34(53.1)$ & $42(65.6)$ & & \\
\hline \multicolumn{5}{|l|}{ ASA } \\
\hline 1 & $2(3.1)$ & $1(1.6)$ & \multirow{3}{*}{$x^{2}=13.147$} & \multirow{3}{*}{0.001} \\
\hline$\|$ & $47(73.4)$ & 28 (43.8) & & \\
\hline III & $15(23.4)$ & $35(54.7)$ & & \\
\hline
\end{tabular}

BMI; Body mass index, BUN; Blood urea nitrogen, GFR; Glomerular filtration rate; AST; Aspartate aminotransferase, ALT; Alanine aminotransferase, Hgb: Hemoglobin, Htc: Hematocrit, WBC: White blood cell, SpO $\mathrm{O}_{2}$ Peripheral oxygen saturation, TUR-B; Transurethral resection of the bladder, TUR-P; Transurethral resection of the prostate, ASA; American Society of Anesthesiologists 
rate of hypotension was higher in patients treated with $15 \mathrm{mg}$ bupivacaine and lower in patients treated with $12.5 \mathrm{mg}$ bupivacaine $(p<0.05)$. In patients receiving i.v. midazolam for sedation, the rate of hypotension seen in those treated with $2 \mathrm{mg}$ of midazolam was higher than those treated with $1 \mathrm{mg}$ $(p<0.05)$. The rate of hypotension was higher in patients whose block level was up to T8, and the rate of hypotension was lower in patients with sensory block levels of T10 and below ( $<$ 0.01) (Table 2).
Group $H$ had slightly lower MSI values than Group N ( $p<0.05)$, while the SI and SIA values were identical between the groups (Table 3, p > 0.05).

Though SI and SIA's success in separating hypotension was not significant ( $p>0.05)$, MSI's performance was significant $(p<0.05)$, and the best cutoff point was 0.73 (Table 4).

The female gender raises the risk of developing hypotension 20.047 fold, a CCl scores increase of 1 point increases risk 2.058 fold, an application zone

Table 2. Comparison of Spinal Needle Thickness, Intrathecal Bupivacaine Dosage, Intravenous Midazolam and Fentanyl Dosages, and Spinal Anesthesia Sensory Block Levels of Normotensive Patients (Group N) and Hypotensive Patients (Group H)

\begin{tabular}{|c|c|c|c|c|c|c|}
\hline & \multicolumn{2}{|c|}{ Group N } & \multicolumn{2}{|c|}{ Group H } & \multirow{2}{*}{ Test statistics } & \multirow{2}{*}{$p$} \\
\hline & $\mathrm{n}$ & $\%$ & $\mathbf{N}$ & $\%$ & & \\
\hline \multicolumn{7}{|l|}{ Spinal needle thickness } \\
\hline $25 G$ & 44 & 68.6 & 50 & 78.1 & \multirow{3}{*}{$x^{2}=2.350$} & \multirow{3}{*}{0.309} \\
\hline $26 G$ & 16 & 25 & 13 & 20.3 & & \\
\hline $27 G$ & 4 & 6.2 & 1 & 1.6 & & \\
\hline \multicolumn{7}{|l|}{ Bupivacaine dosage } \\
\hline $12.5 \mathrm{mg}$ & 41 & 64.1 & 29 & 45.3 & \multirow{3}{*}{$x^{2}=5.441$} & \multirow{3}{*}{0.046} \\
\hline $15 \mathrm{mg}$ & 23 & 35.9 & 33 & 51.6 & & \\
\hline $12.5+10$ mcg fentanyl & 0 & 0 & 2 & 3.1 & & \\
\hline \multicolumn{7}{|l|}{ Midazolam dosage } \\
\hline $1 \mathrm{mg}$ & 37 & 90.2 & 32 & 72.7 & \multirow{2}{*}{$x^{2}=4.262$} & \multirow{2}{*}{0.039} \\
\hline $2 \mathrm{mg}$ & 4 & 9.8 & 12 & 27.3 & & \\
\hline \multicolumn{7}{|l|}{ Fentanyl dosage } \\
\hline $50 \mathrm{mcg}$ & 8 & 88.9 & 12 & 85 & \multirow{3}{*}{$\begin{array}{c}\text { Comparison could } \\
\text { not be made due to } \\
\text { low number }\end{array}$} & \\
\hline $75 \mathrm{mcg}$ & 1 & 11.1 & 0 & 0 & & \\
\hline $100 \mathrm{mcg}$ & 0 & 0 & 2 & 14.3 & & \\
\hline \multicolumn{7}{|l|}{ Sensory block level } \\
\hline T6 & 0 & 0 & 4 & 6.2 & \multirow{4}{*}{$x^{2}=13.815$} & \multirow{4}{*}{0.002} \\
\hline T8 & 10 & 15.6 & 24 & 37.5 & & \\
\hline T10 & 47 & 73.4 & 33 & 51.6 & & \\
\hline $\mathrm{T} 12$ & 7 & 10.9 & 3 & 4.7 & & \\
\hline
\end{tabular}


Table 3. Comparison of Preoperative Shock Index, Modified Shock Index and Shock Index by Age Values of Normotensive Patients (Group N) and Hypotensive Patients (Group H)

\begin{tabular}{|c|c|c|c|c|}
\hline \multirow{2}{*}{ Preoperative } & Group N & Group H & \multirow{2}{*}{ Test Statistics } & \multirow{2}{*}{$p$} \\
\hline & $\begin{array}{c}\text { Mean } \pm \text { SD } \\
\text { Median (Min-Max) }\end{array}$ & $\begin{array}{c}\text { Mean } \pm \text { SD } \\
\text { Median (Min-Max) }\end{array}$ & & \\
\hline Shock Index (SI) & $\begin{array}{c}0.55 \pm 0.10 \\
0.55(0.39-1.02) \\
\end{array}$ & $\begin{array}{c}0.52 \pm 0.12 \\
0.51(0.31-0.81) \\
\end{array}$ & $U=1730.0$ & 0.129 \\
\hline Modified Shock Index (MSI) & $\begin{array}{c}0.78 \pm 0.13 \\
0.78(0.54-1.31)\end{array}$ & $\begin{array}{c}0.73 \pm 0.17 \\
0.71(0.34-1.25)\end{array}$ & $U=1616.0$ & 0.039 \\
\hline Shock index by Age (SIA) & $\begin{array}{c}40.28 \pm 8.34 \\
39.38(28.12-70.97)\end{array}$ & $\begin{array}{c}39.20 \pm 8.44 \\
40.11(21.20-55.33)\end{array}$ & $U=2037.0$ & 0.958 \\
\hline
\end{tabular}

Table 4. Performance of Shock Index, Modified Shock Index, and Shock Index by Age Values in Distinguishing Between Hypotensive and Normotensive Patients*

\begin{tabular}{|c|c|c|c|c|}
\hline & AUC & $95 \% \mathrm{Cl}$ & p & Treshold \\
\hline Shock Index (SI) & 0.578 & $0.478-0.677$ & 0.130 & - \\
\hline Modified Shock Index (MSI) & 0.605 & $0.507-0.704$ & 0.040 & $\leq 0.73$ \\
\hline Shock index by Age (SIA) & 0.503 & $0.402-0.604$ & 0.958 & - \\
\hline
\end{tabular}

*The power of Shock Index, Modified Shock Index, and Shock Index by Age values in discriminating between being hypotensive vs normotensive was evaluated via the area under the ROC curve (AUC). The best cut-off point was calculated using the Youden's Index.

level of L3-L4 increases risk by 199.594 fold as compared to L5-S1, and L4-L5 increases risk by 80.206 fold as compared to L5-S1 according to the logistic model developed with variables that influence the development of hypotension (Table 5).

In Group N, 9.4\% of the patients $(n=6)$ and $20.3 \%$ of the patients in Group $\mathrm{H}(\mathrm{n}=13)$ were hospitalized in the PACU ( $p=0.082)$. In terms of discharge time, there was no substantial difference between Groups N and H (3.55 \pm 5.34 and 4.59 \pm 6.48 respectively; $\mathrm{p}=0.314$ ).

The amount of intraoperative i.v. crystalloid administered and the amount of bladder irrigation fluids (mannitol, crystalloid) used did not vary be- tween the groups, and no patients developed TUR syndrome $(p=0.810, p=0.579$ and $p=0.845$, respectively).

Regarding preoperative patients with MSI values greater than or less than 0.73 , there were no differences in PACU admission $(n=10,15.3 \%$ and $\mathrm{n}=914.5 \%, \mathrm{p}=0.920$, respectively) or postoperative complication rates $(n=5,7.6 \%$ and $n=2,3.2 \%$, $p=0.279$, respectively). Acute renal dysfunction was observed in four patients in the postoperative period in the MSI>0.73 group; dyspnea and shortterm desaturation were seen in two patients, and bladder perforation was seen in one patient in the $\mathrm{MSI} \leq 0.73$ group. 
Table 5. Outcome of Logistic Regression Model for Risk Factors Affecting Development of Hypotension

\begin{tabular}{|l|c|c|c|c|c|}
\hline \multicolumn{1}{|c|}{ Variable } & $\begin{array}{c}\text { Regression } \\
\text { Coefficient (SE) }\end{array}$ & OR & \multicolumn{2}{c|}{$95 \% \mathrm{Cl}$} & P \\
\hline Gender (Female) & $2.998(1.321)$ & 20.047 & 1.506 & 266.917 & 0.023 \\
\hline Charlson Index & $0.722(0.209)$ & 2.058 & 1.367 & 3.097 & 0.001 \\
\hline Level Application & & & & & 0.000 \\
\hline L3-L4 & $5.296(1.301)$ & 199.594 & 15.578 & 2557.374 & 0.000 \\
\hline L4-L5 & $4.385(1.273)$ & 80.206 & 6.621 & 971.625 & 0.001 \\
\hline
\end{tabular}

*In examining the risk factors affecting the development of hypotension, the independent variables found to be significant in the univariate analysis were included in the Multivariate Logistic regression analysis, and the result was a multivariate logistic regression model that included the Backward LR method.

\section{DISCUSSION}

This study found the incidence of postspinal hypotension after spinal anesthesia to be $50 \%$, in patients over 65 years of age who underwent TUR-B and TUR-P surgery under spinal anesthesia. In the adult population, the incidence of hypotension after spinal anesthesia varies from $15 \%$ to $30 \%$ according to the literature (19). The differences in incidence are due to differences in the definition of hypotention used by the studies, as well as variations in the baseline threshold (20). Furthermore, the risk of hypotension increases with age, although the incidence differs depending on factors such as the type and dosage of local anesthetic used, the patients' comorbidities and anthropometric characteristics, and the level of spinal anesthesia (5). The ages of hypotensive patients were found to be higher than those of non-hypotensive patients in our study. Hypotensive patients were shorter in height, and their $\mathrm{CCl}$ and ASA scores were higher than those who were non-hypotensive. Patients with spinal application levels of L3-L4 and female gender were found to have higher levels of hypotension.

Most studies investigating hypotension in elderly patients following spinal anesthesia have focused on major and complicated operations, such as orthopedic surgery. For example, in elective ar- throplastic operations performed under spinal anesthesia in patients $>65$ years of age, Jakobsson et al. discovered a rate of postspinal hypotension of $50 \%(21)$.

In line with the literature, our findings indicate that the incidence of postspinal hypotension in elective urological surgery is significantly higher.

During the aging period, the cardiovascular system undergoes several major changes. In elderly patients who arrive at the operating room, systemic vascular resistance (SVR) is usually high, but accompanying dehydration is a very common complication. Due to reduced stroke volume, SVR, and preload, these patients' hemodynamic status can be compromised during spinal anesthesia $(2,22)$. Intraoperative hypotension may develop following spinal anesthesia. Intraoperative hypotension can lead to severe complications, prolonging hospital stays, and significantly affecting mortality rates (23). Anticipating hypotension after spinal anesthesia can save time in terms of deciding on, preparing, and implementing preventive measures.

Non-invasive methods requiring advanced technology, such as invasive transthoracic echocardiography and the ultrasonic measurement of the inferior vena cava diameter, as well as the hypoten- 
sion prediction index obtained from arterial pulse waveform analysis, are used to predict hypotension $(22,24)$. However, in routine anesthetic practice, these techniques cannot be used in every case. In this study, we investigated whether SI, MSI, and SIA have predictive value for post-spinal hypotension in elderly patients and found that MSI can be used as a practical bedside test to predict hypotension after spinal anesthesia. According to our review of the literature, studies of SI, MSI, and SIA concentrate on sepsis, trauma surgery, major orthopedic surgery, and obstetrics, and ours is the first study on this issue in elective minor urological surgery (9-18).

While SI and SIA were not found to be significant in predicting hypotension in our study, MSI was found to be significant in this regard. This index has a cut-off point of $<0.73$. Additionally, MSI reflects stroke volume and SVR. A high MSI (>1.3) suggests a low stroke volume and a low SVR, both of which are indicators of hypodynamic circulation. These patients' decompensation was rapid, particularly in occult hemorrhagic situations. A low MSI $(<0.7)$ suggests a high SVR and a hyperdynamic state in the patient, which may indicate severe conditions. As a potential predictor of mortality, a high or low $\mathrm{MSI}$ is a stronger parameter than HR, SBP, DBP, and $\mathrm{SI}$ alone $(10,11)$. Except in the absence of severe hypovolemic or septic shock, we noticed that a cut-off point of $<0.73$ is a strong indicator of hypotension due to spinal anesthesia in minor elective surgeries.

After neuraxial blockade, vasodilatory changes that may affect cardiac performance are dependent on the patient's initial sympathetic tone (a higher sympathetic tone equates to a greater hemodynamic change, particularly in the elderly) and the extent of sympathectomy (the level of the sensory block). The elderly have a different physiology than young patients regarding the hypotension caused by spinal anesthesia. Specifically, SVR drops by about $25 \%$, central venous pressure drops by about $3 \mathrm{mmHg}$, and left ventricular end-diastolic pressure drops by about $20 \%$ at the T4-T6 sensory levels of spinal anesthesia. Furthermore, elderly patients have a higher resting sympathetic tone than younger patients, which explains why SVR drops so dramatically after the sympathetic blockade (22). Given these physiological characteristics, it is reasonable to conclude that elderly patients with high SVR and low MSI values $(<0.73)$ due to preoperative hypertension are more susceptible to the risk of hypotension due to the effects of spinal anesthesia.

Increased block height is linked to advanced age. In elderly patients, the specific gravity of the cerebrospinal fluid increases as the volume of the fluid decreases. Furthermore, the nerve roots in the elderly tend to be more susceptible to local anesthesia (25). Patients with a sensory block level of T8 or higher and a bupivacaine dose of more than 12.5 $\mathrm{mg}$ had a higher incidence of hypotension in our study.

We reasoned that the SIA values in our sample were insignificant because the study population did not include all adult age groups and only minor age changes in patients above 65 years of age had no effect on the index.

In our study, postoperative complication rates, postoperative biochemical data, PACU hospitalization, and discharge time did not vary between hypotensive and normotensive patients. Long-term hypotension exposure is required for the development of postoperative adverse outcomes, according to the literature (3). It is possible that the lack of adverse outcomes in our study was due to effective fluid resuscitation and the use of necessary vasopressor therapy to avoid long-term hypotension.

One of our study's limitations was that patients of the female gender (10.2\%) were quite uncommon because the male gender is more common in the patient population for urological surgery. Despite the fact that we achieved the target sample size, research with a greater number of patients and different minor surgeries performed under spinal anesthesia in elderly patients would be more reliable for the value of SI, SIA, and MSI in predicting hy- 
potension. Similarly, the heterogeneity of the ratios of the spinal anesthesia administrations at different levels of the intervertebral space makes it difficult to discuss statistical significance. Moreover, our study design (being observational, not having a standardized anesthetic approach) was an other limitation itself.

\section{CONCLUSION}

Aside from standard hemodynamic monitoring, non-invasive derivative monitoring methods such as $\mathrm{SI}, \mathrm{MSI}$, and SIA may predict hypotension in ger-

\section{REFERENCES}

1. Phillip B, Pastor D, Bellows W. et al. The prevalence of preoperative diastolic filling abnormalities in geriatric surgical patients. Anesth Analg. 2003;97(5):121421. (PMID: 14570626)

2. Hofhuizen C, Lemson J, Snoeck M,et al. Spinal anesthesia-induced hypotension is caused by a decrease in stroke volume in elderly patients. Local Reg Anesth. 2019;12:19-26. (PMID: 30881108)

3. Wesselink EM, Kappen TH, Torn HM, et al. Intraoperative hypotension and the risk of postoperative adverse outcomes: a systematic review. $\mathrm{Br} \mathrm{J}$ Anaesth. 2018;121(4):706-21. (PMID: 30236233)

4. Kheterpal S, O'Reilly M, Englesbe MJ, et al. Preoperative and intraoperative predictors of cardiac adverse events after general, vascular, and urological surgery. Anesthesiology. 2009;110(1):58-66. (PMID: 19104171)

5. Walsh M, Devereaux PJ, Garg AX, et al. Relationship between intraoperative mean arterial pressure and clinical outcomes after noncardiac surgery: toward an empirical definition of hypotension. Anesthesiology. 2013;119(3):507-15. (PMID: 23835589)

6. Sun LY, Wijeysundera DN, Tait GA, et al. Association of intraoperative hypotension with acute kidney injury after elective noncardiac surgery. Anesthesiology. 2015;123(3):515-23. (PMID: 26181335)

7. Kratz T, Hinterobermaier J, Timmesfeld N, et al. Pre-operative fluid bolus for improved haemodynamic stability during minor surgery: a prospective- iatric patients due to their hemodynamically pathophysiological characteristics. In elderly patients, MSI based on MAP, which tests tissue perfusion, may be more significant in predicting hypotension.

Acknowledgements: Permissions have been obtained from the patients for presentation.

Funding: No funding was used for this study.

Conflict of interest statement: The authors state that they have no conflict of interest in this study.

ly randomized clinical trial. Acta anaesthesiologica Scandinavica. 2018;62(9):1215-22. (PMID: 29851024)

8. Minto G, Scott MJ, Miller TE. Monitoring needs and goal-directed fluid therapy within an enhanced recovery program. Anesthesiol Clin. 2015;33(1):35-49. (PMID: 25701927)

9. Birkhahn RH, Gaeta TJ, Terry D, et al. Shock index in diagnosing early acute hypovolemia. Am J Emerg Med. 2005;23(3):323-6. (PMID: 15915406)

10. Singh A, Ali S, Agarwal A, et al. Correlation of shock index and modified shock index with the outcome of adult trauma patients: a prospective study of 9860 patients. N Am J Med Sci. 2014;6(9):450-2. (PMID: 25317389)

11. Liu YC, Liu JH, Fang ZA, et al. Modified shock index and mortality rate of emergency patients. World $\mathrm{J}$ Emerg Med. 2012;3(2):114-7. (PMID: 25215048)

12. Zarzaur BL, Croce MA, Fischer PE, et al. New vitals after injury: shock index for the young and age $x$ shock index for the old. J Surg Res. 2008;147(2):22936. (PMID: 18498875)

13. Kuhne CA, Ruchholtz S, Kaiser GM, et al. Mortality in severely injured elderly trauma patients--when does age become a risk factor? World J Surg. 2005;29(11):1476-82. (PMID: 16228923)

14. Kim SY, Hong KJ, Shin SD et al. Validation of the Shock Index, Modified Shock Index, and Age Shock Index for predicting mortality of geriatric trauma patients in emergency departments. J Korean Med Sci. 2016;31(12):2026-32. (PMID: 27822945) 
15. Lee K, Jang JS, Kim J, et al. Age shock index, shock index, and modified shock index for predicting postintubation hypotension in the emergency department. The American journal of emergency medicine. 2020;38(5):911-5. (PMID: 31345593)

16. Trivedi S, Demirci $O$, Arteaga G, et al. Evaluation of preintubation shock index and modified shock index as predictors of postintubation hypotension and other short-term outcomes. Journal of critical care. 2015;30(4):861. e1-. e7. (PMID: 25959037)

17. Bhandarkar P, Munivenkatappa A, Roy N, et al. Pattern and distribution of Shock Index and Age Shock Index Score among trauma patients in Towards Improved Trauma Care Outcomes (TITCO) Dataset. Bull Emerg Trauma. 2018;6(4):313-7. (PMID: 30402519)

18. Mutschler M, Nienaber $U$, Münzberg $M$, et al. The Shock Index revisited - a fast guide to transfusion requirement? A retrospective analysis on 21,853 patients derived from the TraumaRegister DGU. Crit Care. 2013;17(4):R172. (PMID: 23938104)

19. Hartmann B, Junger A, Klasen J, et al. The incidence and risk factors for hypotension after spinal anesthesia induction: an analysis with automated data collection. Anesth Analg. 2002;94(6):1521-9, table of contents. (PMID: 12032019)

20. Ngu JMC, Jabagi $H$, Chung AM, et al. Defining an intraoperative hypotension threshold in association with de novo renal replacement therapy after cardiac surgery. Anesthesiology. 2020;132(6):1447-57. (PMID: 32205546)

21. Jakobsson J, Kalman S, Lindeberg-Lindvet $M$, et al. Is postspinal hypotension a sign of impaired cardiac performance in the elderly? An observational mechanistic study. BJA: British Journal of Anaesthesia. 2017;119(6):1178-85. (PMID: 29040402)

22. Ceruti S, Anselmi L, Minotti B, et al. Prevention of arterial hypotension after spinal anaesthesia using vena cava ultrasound to guide fluid management. $\mathrm{Br}$ J Anaesth. 2018;120(1):101-8. (PMID: 29397116)

23. Sessler DI, Bloomstone JA, Aronson S, et al. Perioperative Quality Initiative consensus statement on intraoperative blood pressure, risk and outcomes for elective surgery. Br J Anaesth. 2019;122(5):563-74. (PMID: 30916004)

24. Davies SJ, Vistisen ST, Jian Z, et al. Ability of an arterial waveform analysis-derived hypotension prediction index to predict future hypotensive events in surgical patients. Anesthesia \& Analgesia. 2020;130(2):352-9. (PMID: 30896602)

25. Brull R, Macfarlane AJ, Chan VW. Spinal, Epidural, and Caudal Anesthesia, In: Ronald Miller, Lars Eriksson, Lee Fleisher (Eds). Miller's Anesthesia. 8th edition, Elsevier, USA 2015, pp 1684-716. 